\title{
Model predictive control of fuel cell micro cogeneration systems*
}

\author{
M. Houwing, R.R. Negenborn, M.D. Ilić, and B. De Schutter
}

If you want to cite this report, please use the following reference instead:

M. Houwing, R.R. Negenborn, M.D. Ilić, and B. De Schutter, "Model predictive control of fuel cell micro cogeneration systems," Proceedings of the 2009 IEEE International Conference on Networking, Sensing and Control, Okayama, Japan, pp. 708-713, Mar. 2009.

Delft Center for Systems and Control

Delft University of Technology

Mekelweg 2, 2628 CD Delft

The Netherlands

phone: +31-15-278.24.73 (secretary)

URL: https: //www.dcsc.tudelft.nl

*This report can also be downloaded viahttps://pub.deschutter.info/abs/09_016.html 


\title{
Model Predictive Control of Fuel Cell Micro Cogeneration Systems
}

\author{
Michiel Houwing, Rudy R. Negenborn, Marija D. Ilić, and Bart De Schutter
}

\begin{abstract}
With the increasing application of distributed energy resources and information technologies in the electricity infrastructure, innovative possibilities for incorporating the demand side more actively in power system operation are enabled. At the residential level energy costs could be reduced with intelligent price-based control concepts (demand response). A promising, controllable, residential distributed generation technology is micro cogeneration (micro-CHP). Micro-CHP is an energy efficient technology that simultaneously provides heat and electricity to households during operation. This paper presents a detailed model of a household using a proton exchange membrane fuel cell (PEMFC) micro-CHP system in conjunction with heat storage options to fulfil its heat and part of its electricity demand. Furthermore, a decentralised controller based on a model predictive control (MPC) strategy is proposed. MPC can take benefit of future knowledge on prizes and energy demands and can therefore lead to better system performance. In simulations the performance of the MPC-controlled PEMFC system is illustrated under different conditions regarding energy pricing, domestic energy demand, and system configuration.
\end{abstract}

Index Terms-Demand response, distributed energy resources, PEM fuel cells, micro cogeneration, model predictive control.

\section{INTRODUCTION}

Distributed energy resources (DERs) are expected to play a significant role in future electricity supply. The concept of DERs comprises distributed electricity gene-ration, distributed energy storage, and responsive energy loads. DERs can play a crucial role in achieving key policy objectives such as facilitating electricity market liberalisation, mitigating climate change, improving power system reliability, and enhancing economic efficiency of the power industry. Via novel information technology (IT) systems (e.g., intelligent

Manuscript received December 15, 2008. This work was supported by the Next Generation Infrastructures Foundation, the European STREP project "Hierarchical and distributed model predictive control (HD-MPC)", the project "Multi-Agent Control of Large-Scale Hybrid Systems" (DWV.6188) of the Dutch Technology Foundation STW, and by the US NSF ITR project, number CNS0428404.

M. Houwing is with the Faculty of Technology, Policy and Management of Delft University of Technology, Jaffalaan 5, 2628 BX Delft, The Netherlands and guest of the Electric Energy Systems Group of Carnegie Mellon University, Pittsburgh, PA, USA (corresponding author, phone: +310152781340; fax: +310152783422; e-mail: M.Houwing@tudelft.nl).

M. D. Ilić is with the Departments of Electrical and Computer Engineering and Engineering and Public Policy, Carnegie Mellon University, Pittsburgh, PA, USA, and she is Honorary Chair Professor for Control of Future Electricity Network Operations at the Faculty of Technology, Policy and Management of Delft University of Technology, Delft, The Netherlands (e-mail: Milic@ece.cmu.edu).

R.R. Negenborn and B. De Schutter are with the Delft Center for Systems and Control of Delft University of Technology, Mekelweg 2, 2628 CD Delft, The Netherlands (e-mail: R.R.Negenborn@tudelft.nl, B@deschutter.info). B. De Schutter is also with the Marine and Transport Technology department of Delft University of Technology. metering and control) the demand side can be more actively incorporated into socio-technical power system operation (i.e., technical and market operations). DERs can be used for different objectives. Control can be aimed at ensuring technical reliability (e.g., frequency control), control could optimise environmental benefits (e.g., by facilitating the integration of intermittent renewable resources), or control can be applied for cost minimisation (e.g., active market participation, price-based control). In this paper we focus on the latter. Price-based response of electricity demand is referred to as demand response. DERs thereby become demand response resources. Demand response can increase economic efficiency by enabling electricity demand to respond to variations in electricity prices. System peaks can be lowered by reducing demand and/or by shifting demand to cheaper times and/or by self generation of power, thereby reducing costs and increasing capacity utilisation of capital intensive systems. Therefore, social benefit is created by embedding IT into DERs.

This paper focuses on micro cogeneration, or micro combined heat-and-power, technology (micro-CHP), which is a residential level distributed generation system. Micro-CHP technology is very promising for certain countries, mainly depending on their climate (i.e., substantial heat demand is required) and the extent of their gas networks. Potential markets are Northern and North-Western Europe, Northern Italy, North America, and Japan. Applying micro-CHP leads to more efficient domestic energy use, reliability improvements, carbon emission reductions, and to substantial energy cost savings of around 10-20\% per household [1]. Micro-CHP is part of the transition towards a society fully relying on renewable energy resources. Contrary to distributed generation technologies that depend on intermittent primary energy sources (e.g., photovoltaic systems depend on the sun and wind turbines depend on wind), micro-CHP is a special case in the sense that it is controllable.

It is our hypothesis that intelligent micro-CHP control reduces operational energy costs when compared to more simple thermal-led control of micro-CHPs, thereby improving the return on capital investment. In our definition, intelligent control means the capability to anticipate future information on energy demand and energy tariffs and incorporating this information into control actions. This could then be called intelligent demand response. A particular intelligent control technique is model predictive control (MPC) [2]. MPC may become very interesting when households receive more realtime electricity pricing. At present, residential consumers get flat rates, but energy companies could provide the service of real-time (e.g., hourly) prices. If MPC benefits from 
real-time prices, customers in the competitive retail market could be captured and cost benefits could be shared between households and energy companies offering the service. Thus, intelligent control might open up new business opportunities for households and energy companies [3]. Governments could also oblige energy companies to provide the real-time pricing service to households.

The hypothesis that MPC reduces operational costs was already illustrated in [3] for Stirling micro-CHP systems. In [3], however, it was found that only under specific electricity pricing regimes MPC control is beneficial. Besides Stirling technology, fuel cells are a second promising conversion technology for micro-CHP. The two main differences between fuel cells and Stirling engines are the significantly higher electrical efficiency (i.e., lower heat-to-power ratio) and the higher electric capacity of fuel cell systems when compared to Stirling micro-CHPs [1]. Due to these inherently different technical characteristics it is interesting to investigate the possible cost reductions with MPC applied to fuel cell micro-CHP systems.

Developing good models of fuel cell micro-CHP systems as well as designing the accompanying MPC strategy are far from being straightforward tasks. This paper presents a detailed fuel cell micro-CHP prediction model, it deals with the MPC controller design, and provides insight into the performance of MPC-controlled fuel cell micro-CHPs.

This paper is organised as follows. In Section II we describe a specific fuel cell micro-CHP system; conceptually and mathematically. Section III deals with the design and modelling of thermal-led and intelligent MPC control strategies for the micro-CHP system. The model parameters, model input and simulation results are presented in Section IV. Finally, Section V presents our conclusions and recommendations for further research.

\section{SySTEM DESCRIPTION}

\section{A. Household System Description}

The household system analysed in this paper is conceptually depicted in Fig. 1. The household can fulfil its electricity and heat demand through several alternative means. The micro-CHP unit consists of a fuel cell unit and an auxiliary burner. The auxiliary burner can provide additional heat when necessary. The fuel cell is of the proton exchange membrane type, which is also known as a polymer electrolyte membrane fuel cell (PEMFC). Solid oxide fuel cells are also possible in micro-CHP systems [4], but as a first technology we look at PEMFC. In reality natural gas to be used by the PEMFC is first reformed into hydrogen that is subsequently electrochemically converted in the fuel cell. For this reforming process some natural gas is used. For modelling purposes we define two separate gas streams that enter the fuel cell: $f_{\mathrm{r}}$ is gas used solely for heating the reforming unit and $f_{1}$ represents the total gas flow to the fuel cell system (including gas for reforming). As long as the fuel cell runs at relatively high capacity only $f_{1}$ is considered, but at lower output $f_{\mathrm{r}}$ becomes of importance. This will be explained in more detail further on in this

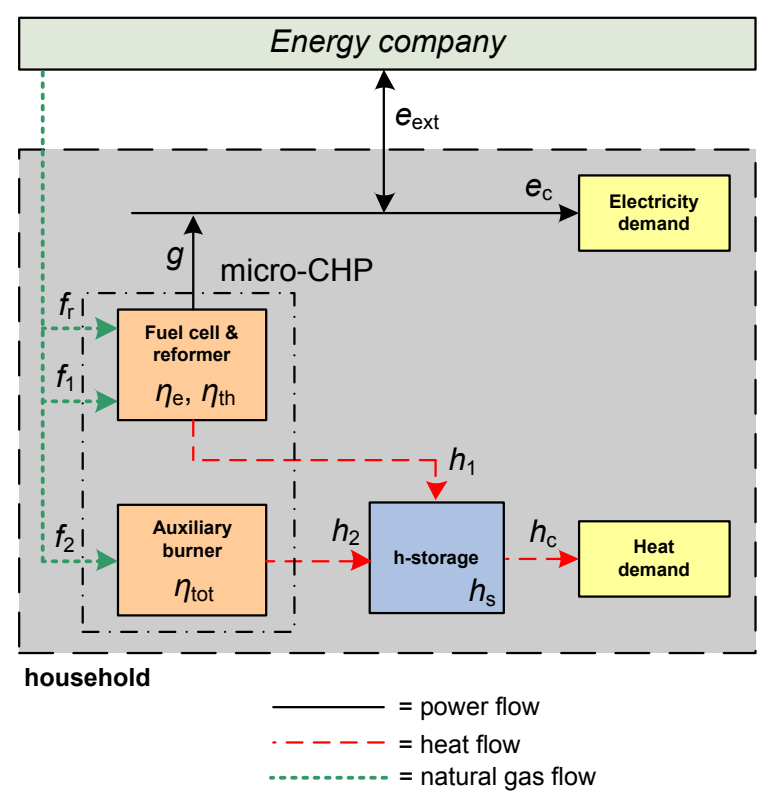

Fig. 1. Conceptual overview of a household with a fuel cell micro-CHP system.

section. The fuel cell converts natural gas $\left(f_{1}\right)$ into electrical energy $(g)$ and heat $\left(h_{1}\right)$. The heat is supplied in the form of hot water to a central heat storage, the energy content of which is indicated by $h_{\mathrm{s}}$. Many different in-house heating configurations are possible (see, e.g., [5]), but we choose a configuration with one large heat storage from which all heat demand is taken, as this improves the options for flexible control. The auxiliary burner also converts natural gas $\left(f_{2}\right)$ into additional heat $\left(h_{2}\right)$. Heat consumption (i.e., aggregated space heating and domestic hot water needs) $\left(h_{\mathrm{c}}\right)$ is taken from the heat storage. Electricity generated by the fuel cell can be used directly by the household $\left(e_{\mathrm{c}}\right)$ or it can be sold to the external energy company $\left(e_{\text {ext }}\right)$. Electricity can also be imported from the company. The energy company thus sells primary fuel $\left(f_{\mathrm{r}}+f_{1}+f_{2}\right)$ as well as electricity to the household. The energy company receives exported electricity from the household and possibly pays households a certain feed-back tariff for this electricity.

\section{B. Mathematical System Model Formulation}

Since we are interested in MPC, we have to construct a suitable prediction model of the system of Fig. 1. In this section such a mathematical model is presented. The household is a hybrid system in the sense that it exhibits both continuous and discrete dynamics. Continuously evolving dynamics (e.g., heat consumption) are present in combination with discrete events (e.g., on/off control of fuel cell). We formulate the model in terms of linear mixed-integer equality and inequality constraints (i.e., constraints involving both variables taking on values from a continuous set, and variables taking on values from an integer set), since optimisation problem solvers that can deal with these constraints are available [6]. It is important to note that our simulation 
time steps represent 15 minute periods and that continuous dynamics are therefore discretised into finite steps.

First we define the binary variables $v_{k}^{\mathrm{FC}}$ and $v_{k}^{\text {aux }}$, which indicate whether the PEMFC and auxiliary burner are in operation at a specific time step $k$. In addition, the binary variables $u_{\text {up }, k}^{\mathrm{FC}}, u_{\mathrm{down}, k}^{\mathrm{FC}}$ and $u_{\mathrm{up}, k}^{\mathrm{aux}}, u_{\mathrm{down}, k}^{\text {aux }}$ are start-up and shut-down indicators for the fuel cell and auxiliary burner, respectively, at time step $k$.

An electric energy balance has to be satisfied each $k$, relating the electric power output of the PEMFC, the electricity consumption and electricity exchanged with the energy company $\left(e_{\mathrm{ext}}\right)$. This power balance is given by:

$$
e_{\mathrm{c}, k}-g_{k}=e_{\mathrm{ext}, k} \text {. }
$$

The electric power that can be exchanged between the household and the external grid is limited. Therefore a constraint on the import and export power flow is required:

$$
\begin{aligned}
& e_{\mathrm{ext}, k} \leq P_{\max }, \\
& -P_{\max } \leq e_{\mathrm{ext}, k},
\end{aligned}
$$

where $P_{\max }$ is the maximum power flow allowed through the physical connection between the household and the external network.

In reality, the electric efficiency of fuel cells decreases with increasing electric output capacity [7]. For modelling convenience, however, we assume efficiencies (electric, $\eta_{\mathrm{e}}$, and thermal, $\eta_{\text {th }}$ ) to be constant over system capacity.

The gas used by the PEMFC is modelled by

$$
f_{1, k}=\frac{g_{k}}{\eta_{\mathrm{e}}} .
$$

The electric power output of the PEMFC can modulate between a minimum and maximum load, modelled by the constraints:

$$
\begin{aligned}
& g_{k} \leq v_{k}^{\mathrm{FC}} \cdot g_{\max } \\
& g_{k} \geq v_{k}^{\mathrm{FC}} \cdot g_{\min } .
\end{aligned}
$$

The fuel cell itself can ramp up and down in output capacity very quickly. The reforming unit, however, limits this ramp rate [8]. The ramp-up rate and ramp-down rates of the electric power output of the fuel cell are assumed to be equal (see [7]) and we model them by:

$$
\begin{aligned}
& g_{k+1} \leq g_{k}+g_{\text {ramp }} \\
& g_{k+1} \geq g_{k}-g_{\text {ramp }},
\end{aligned}
$$

where $g_{\text {ramp }}$ is the ramp rate in, e.g., $\mathrm{kW} / \mathrm{min}$.

The fuel cell system can be in the on-position, but produce almost no or even zero electricity or usable heat. This is different from being in the off-position, because then the system would have to go through a cold/hot start period before being able to produce electricity and usable heat again. When standing idle, the system can instantly produce electricity and heat again. Being in the on-position and not producing usable energy, however, requires gas for keeping the reforming unit at a certain temperature (around $900^{\circ} \mathrm{C}$ ). This amount of gas is denoted by $f_{\mathrm{r}}$. When the PEMFC is running at very low capacity we ensure that the total gas consumption cannot go below $f_{\mathrm{r}}$ by introducing the following logic statement:

$$
\begin{aligned}
& \text { if } f_{1, k}<f_{\mathrm{r}} \wedge v_{k}^{F C}=1 \text { then } f_{\mathrm{r}, k}=f_{\mathrm{r}}-f_{1, k} \\
& \text { else } f_{\mathrm{r}, k}=0
\end{aligned}
$$

which introduces a new variable $f_{\mathrm{r}, k}$.

For the fuel cell the minimum up and down times are assumed to be equal to one time step [9]. During cold and hot start the total fuel cell system (including reformer) has to heat up before it can start to deliver electricity and heat. Cold and hot start take somewhat different amounts of time [9], but we assume them to be equal and denote this time with $t_{\text {start }}$. During hot and cold start the system consumes gas but delivers no electricity and a small amount of heat [9], which we treat as being negligible. The amount of gas used during cold and hot start is assumed to be equal to the previously mentioned $f_{\mathrm{r}}$. The start-up procedure is then modelled by:

$$
v_{k+n}^{\mathrm{FC}} \geq u_{\mathrm{up}, k}^{\mathrm{FC}}, \quad n=0, \ldots, t_{\mathrm{start}}-1 .
$$

Further, the following statement is also needed:

$$
\text { if } u_{\mathrm{up}, k}^{\mathrm{FC}}=1 \text { then } g_{k+w}=0, \quad w=0, \ldots, t_{\mathrm{start}}-1,
$$

which ensures that there is no electricity production and gas use ( $f_{1, k}$ is then 0 due to (4)) during start-up. With (9), $f_{\mathrm{r}, k}$ will be equal to $f_{\mathrm{r}}$ during start-up.

The fuel consumption of the auxiliary burner is modelled by:

$$
\begin{aligned}
& f_{2, k} \leq v_{k}^{\text {aux }} \cdot f_{2, \text { max }}, \\
& f_{2, k} \geq v_{k}^{\text {aux }} \cdot f_{2, \text { min }},
\end{aligned}
$$

where $f_{2, \min }$ and $f_{2, \max }$ are the minimal and maximum fuel consumption of the auxiliary burner.

The heat stored should be between minimum and maximum values:

$$
\begin{aligned}
& h_{\mathrm{s}, k} \leq h_{\mathrm{s}, \max }, \\
& h_{\mathrm{s}, k} \geq h_{\mathrm{s}, \text { min }},
\end{aligned}
$$

where $h_{\mathrm{s}, \min }$ and $h_{\mathrm{s}, \max }$ are minimum and maximum energy levels of the heat storage. The heat contained in the heat storage changes over time depending on the heat consumption and generation. The dynamics of the heat storage are modelled by:

$$
\begin{aligned}
& h_{\mathrm{s}, k+1}=(1-l) \cdot h_{\mathrm{s}, k}+h_{1, k}+h_{2, k}-h_{\mathrm{c}, k}, \text { with: } \\
& h_{1, k}=\eta_{\mathrm{th}} \cdot f_{1, k}, \\
& h_{2, k}=\eta_{\mathrm{aux}} \cdot f_{2, k} .
\end{aligned}
$$

In this, $\eta_{\text {aux }}$ is the efficiency of the auxiliary burner, and $l$ is the thermal loss factor.

In order to let the energy systems function as they should, the binary variables $v_{k}^{\mathrm{FC}}, u_{\mathrm{up}, k}^{\mathrm{FC}}$, and $u_{\text {down }, k}^{\mathrm{FC}}$ on the one hand, and $v_{k}^{\text {aux }}, u_{\mathrm{up}, k}^{\text {aux }}$, and $u_{\text {down }, k}^{\text {aux }}$ on the other, have to be linked. 


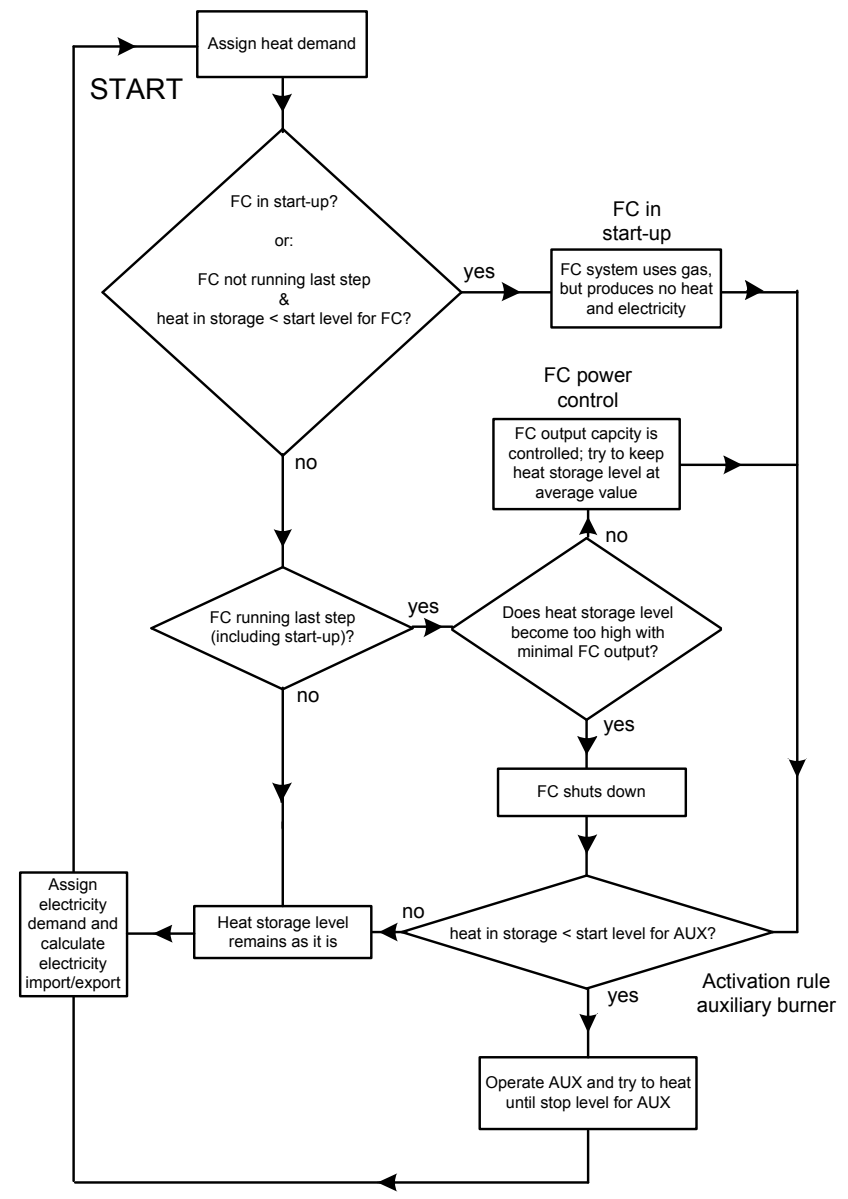

Fig. 2. Algorithm for thermal-led, fuel cell, micro-CHP control ('FC' denotes the fuel cell, 'AUX' denotes the auxiliary burner).

The relations between these variables are:

$$
\begin{aligned}
& v_{k}^{\mathrm{FC}}-v_{k-1}^{\mathrm{FC}}=u_{\text {up }, k}^{\mathrm{FC}}-u_{\text {down }, k}^{\mathrm{FC}} \\
& v_{k}^{\text {aux }}-v_{k-1}^{\text {aux }}=u_{\text {up }, k}^{\text {aux }}-u_{\text {down }, k}^{\text {aux }} \\
& u_{\text {up }, k}^{\mathrm{FC}}+u_{\text {down }, k}^{\mathrm{FC}} \leq 1 \\
& u_{\text {up }, k}^{\text {aux }}+u_{\text {down }, k}^{\text {aux }} \leq 1 .
\end{aligned}
$$

So, there are dynamics in the model due to the presence of the heat storage, the power ramp rates and the start-up time.

\section{Thermal-Led AND Model Predictive Control}

In this section we formulate the MPC control problem, but before doing so we first describe conventional microCHP control, which functions as a reference control strategy against which MPC control is benchmarked.

\section{A. Thermal-Led Control}

In [10] different types of control schemes for generators are defined. The most plausible control strategy envisaged for micro-CHPs when they enter the market is thermal-led control, which means that the system will operate whenever there is a demand for heat. Such a strategy is classified as

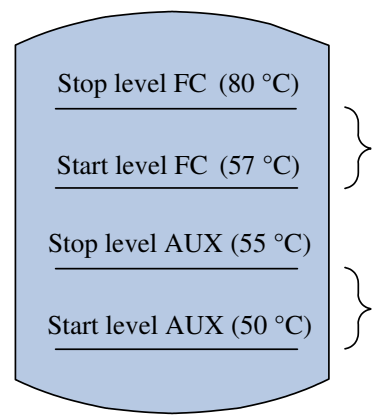

Fig. 3. Temperature levels of the water in the heat storage with which the thermal-led control operates.

stringent control according to [10]. Our developed thermalled control algorithm for a fuel cell micro-CHP system is given in Fig. 2. When the fuel cell system is in its start-up time at a certain step or when it has not been running in the previous step and the temperature level in the heat storage falls below a minimum level, the fuel cell will go in start-up mode. When the fuel cell has been running in the previous time step, it is checked if the fuel cell could keep running with minimum output in the current step without overheating the heat storage. If the heat storage becomes too hot with the minimum output, the fuel cell system is shut down. If it can run, it is tried to operate the fuel cell with such a capacity as to heat the water in the heat storage to its average level. So, the fuel cell and the auxiliary burner are operated based on temperature levels in the heat storage (see Fig. 3, with examples of temperatures). The fuel cell will heat the water from, e.g., a minimum start level of $57^{\circ} \mathrm{C}$, to a maximum of $80^{\circ} \mathrm{C}$. For the auxiliary burner examples of these limits are as in Fig. 3.

Contrary to the prediction model described in Section II, the fuel cell system operates at a non-zero minimum output. If the minimum output could be zero, the fuel cell would stand idle when the average temperature level in the storage is reached, the maximum stop temperature for the fuel cell is never reached and the fuel cell would never stop operating. A further choice in designing the control strategy is whether the fuel cell shuts down completely when having reached its stop temperature or if it should stand idle for a few steps (thereby using gas while producing no usable energy) with the possibility of being able to quickly deliver usable heat and power again. Then, when after a few steps the temperature in the storage has not dropped significantly yet (e.g., below the average temperature), the fuel cell can be shut down completely. As a first option we choose to let the fuel cell shut down completely when reaching the stop temperature and go through a start-up time before being able to produce usable energy again. It is interesting to compare this choice with the other option of possible idle operation after having reached the stop temperature. Comparing the total natural gas use and the number of daily start-ups is interesting then. In the thermal-led control we also incorporate the control as was described in (9) in Section II. So, when the PEMFC is running at very low capacity, the 
total gas consumption cannot go below $f_{\mathrm{r}}$.

\section{B. Model Predictive Control Setup}

The MPC strategy that we propose is a single-agent MPC strategy [11]. At each control step the MPC controller or control agent uses the following information:

- an objective function expressing desired system behaviour and actions;

- a prediction model describing the behaviour of the system subject to actions;

- possibly constraints on the states, the inputs, and the outputs of the system (where the inputs and the outputs of the system correspond to the actions and the measurements of the control agent, respectively);

- possibly known information about future disturbances;

- a measurement of the state of the system at beginning of the current control step.

In our case the MPC controller has to determine which actions should be taken in order to minimise the operational costs of fulfilling residential electricity and heat requirements subject to operational constraints. There are distinct and predictable patterns in residential energy demand and energy prices of which MPC can take advantage. The proposed controller uses MPC to:

- take into account the decision freedom due to heat storage possibilities and the different options for heat production with the fuel cell or with the auxiliary burner (According to [10], with MPC the micro-CHP unit now becomes a partially controllable system instead of a stringently controlled system);

- incorporate predictions on residential electricity and heat demands and energy prices;

- incorporate models of the dynamics and constraints of installed generators and storages.

At each control step the controller solves an optimisation problem over a prediction horizon subject to system dynamics, an objective function, and constraints on states, actions, and outputs. The controller applies the computed actions of the first step in the horizon to the system until the next control step, after which the procedure is repeated with new system measurements. Due to the prediction horizon an MPC controller can take benefit of knowledge that it may have about the future.

The objective of the MPC controller is to minimise the operational costs of residential energy use. These costs depend on the price $p_{\mathrm{f}}$ for gas consumption and the (varying) prices of electricity import and export, $p_{\mathrm{i}, \mathrm{ext}}$ and $p_{\mathrm{e}, \mathrm{ext}}$. The cost function for control step $k$ with a prediction horizon of $N$ is therefore defined as:

$$
J(\cdot)=\sum_{m=0}^{N-1}\left(\begin{array}{l}
\left(f_{r, k+m}+f_{1, k+m}+f_{2, k+m}\right) \cdot p_{\mathrm{f}}+ \\
i_{\mathrm{ext}, k+m} \cdot p_{\mathrm{i}, \mathrm{ext}, k+m}-e_{\mathrm{ext}, k+m} \cdot p_{\mathrm{e}, \mathrm{ext}, k+m}
\end{array}\right)
$$

At each time step $k$ the controller formulates its MPC problem over the prediction horizon comprising $N$ prediction steps (the length of each prediction step $m$ is 15 minutes). The resulting optimisation problem involves minimising (23) subject to (1)-(22) over the horizon $N$. Due to the occurrence of both continuous-valued variables and binary-valued variables in combination with a linear objective function and linear equality and inequality constraints, this optimisation problem is a mixed-integer linear programming problem.

The prediction model that the MPC controller uses is described in Section II B. When assessing the performance of the MPC strategy using computer simulations, the control actions have to be implemented in a simulation model of the household. We assume both models to be equal. Furthermore, between simulation steps the start-up time for the fuel cell reformer is taken into account.

\section{Model Parameters and Simulation InPUt}

In [3] we have assumed predicted and real energy demand to be equal to the average of the aggregate domestic profile of the Netherlands. As residential electricity demand is extremely erratic in nature (heat demand is smoother), this is a too stringent assumption when looking at just one household. When the household model of Fig. 1 is regarded as representing a cluster of households, it can be considered to be a virtual power plant (VPP), and the aggregate demand of such a VPP is relatively smooth and predictable. We therefore use the average aggregate profiles here as well, and assume we are dealing with a (small) VPP that undertakes clustered demand response. In designing real-time price tariffs for electricity, up until now we have used Dutch power exchange prices (e.g., in [3]). As only part of the electricity is traded through the power exchange, new real-time prices, which are based on more nation-wide price formation, have been developed. The average of this varying electricity tariff was $0.18 € / \mathrm{kWh}$. We only looked at the situation in which $p_{\mathrm{i} \text {,ext }}$ and $p_{\mathrm{e} \text {,ext }}$ were time-varying and equal to one another. The used gas price was 0.06 $€ / \mathrm{kWh}$. Table I gives values of the model parameters for modelling MPC of the PEMFC household system. Data were obtained from [7-9,12]. Simulations were done for the first three (winter) months in 2006. Four extreme scenarios were analysed, namely:

1) Base: above-mentioned prices and average demand profiles;

2) Half gas price: represents a more industrial tariff;

3) Higher energy demand: twice as large heat and electricity demand;

4) Large heat storage: 500 litres instead of 200 litres.

Results of the simulations (i.e., residential energy costs in $€ / 3$ months) with the thermal-led model and the MPC model are shown in Table II. For the MPC case we only show the results from simulations with a prediction horizon of $N=96$.

From Table II we can see that in all scenarios MPC control has some cost advantage over standard thermal-led control. Cost savings range from 2 to $6 \%$. This means that our hypothesis that was mentioned in Section I has been confirmed. However, the improvement in terms of operational cost savings is not as significant as might be expected. 
TABLE I

PARAMETERS FOR PEMFC HOUSEHOLD SYSTEM

\begin{tabular}{|c|c|c|c|}
\hline Parameter & Description & Value & Unit \\
\hline$\eta_{\mathrm{e}}$ & Electric efficiency of PEMFC & 0.30 & - \\
\hline$\eta_{\text {e_tot }}$ & Total PEMFC efficiency & 0.85 & - \\
\hline$\eta_{\text {aux }}$ & Auxiliary burner efficiency & 1.01 & - \\
\hline$g_{\min }$ & $\begin{array}{l}\text { Minimum electric output capacity of } \\
\text { PEMFC }\end{array}$ & $0^{a}$ & $\mathrm{~kW}$ \\
\hline$g_{\max }$ & $\begin{array}{l}\text { Maximum electric output capacity of } \\
\text { PEMFC }\end{array}$ & 3 & $\mathrm{~kW}$ \\
\hline$g_{\text {ramp }}$ & $\begin{array}{l}\text { Ramp rate (up/down) of electric out- } \\
\text { put capacity of PEMFC }\end{array}$ & 0.15 & $\mathrm{~kW} / \mathrm{min}$ \\
\hline$f_{\mathrm{r}}$ & Gas use for natural gas reforming & 1 & $\mathrm{~kW}$ \\
\hline$t_{\text {start }}$ & $\begin{array}{l}\text { Hot/cold start-up time of PEMFC } \\
\text { system (reformer) }\end{array}$ & 45 & $\min$ \\
\hline$h_{2, \min }$ & $\begin{array}{l}\text { Minimum auxiliary burner thermal } \\
\text { output capacity }\end{array}$ & 4 & $\mathrm{~kW}$ \\
\hline$h_{2, \max }$ & $\begin{array}{l}\text { Maximum auxiliary burner thermal } \\
\text { output capacity }\end{array}$ & 20 & $\mathrm{~kW}$ \\
\hline$T_{\mathrm{s}, \text { start_FC }}$ & $\begin{array}{l}\text { Temperature of heat storage at which } \\
\text { PEMFC starts running }\end{array}$ & 57 & ${ }^{\circ} \mathrm{C}$ \\
\hline$T_{\mathrm{s}, \text { stop_FC }}{ }^{b}$ & $\begin{array}{l}\text { Temperature of heat storage at which } \\
\text { the PEMFC should stop running. } \\
\text { This is the maximum temperature of } \\
\text { heat storage }\end{array}$ & 80 & ${ }^{\circ} \mathrm{C}$ \\
\hline$T_{\mathrm{S}, \text { start_AUX }}$ & $\begin{array}{l}\text { Temperature of heat storage at which } \\
\text { auxiliary burner starts running. This } \\
\text { is the minimum temperature of heat } \\
\text { storage }\end{array}$ & 50 & ${ }^{\circ} \mathrm{C}$ \\
\hline$T_{\mathrm{s}, \mathrm{stop} \_\mathrm{AUX}}$ & $\begin{array}{l}\text { Temperature of heat storage at which } \\
\text { auxiliary burner stops running }\end{array}$ & 55 & ${ }^{\circ} \mathrm{C}$ \\
\hline$m$ & $\begin{array}{l}\text { Mass of the water contained in the } \\
\text { heat storage }\end{array}$ & 200 & $\mathrm{~kg}$ \\
\hline$P_{\max }$ & $\begin{array}{l}\text { Maximum power flow allowed } \\
\text { through the physical connection } \\
\text { between the household and grid }\end{array}$ & 8 & $\mathrm{~kW}$ \\
\hline$l$ & $\begin{array}{l}\text { Thermal loss factor: heat storage } \\
\text { content as fraction of value at pre- } \\
\text { vious step }\end{array}$ & 0.995 & - \\
\hline
\end{tabular}

${ }^{a}$ In the thermal-led mode the minimum PEMFC output is $0.1 \mathrm{~kW}$.

${ }^{b}$ The energy content of the heat storage at a certain $T_{\mathrm{S}}$ is calculated by the formula $h_{\mathrm{s}}=m \cdot c \cdot\left(T_{\mathrm{S}}-T_{\mathrm{env}}\right)$, where $c$ is the specific heat of water, 4.18 $\mathrm{kJ} / \mathrm{kg} \cdot \mathrm{K}$, and $T_{\mathrm{env}}$ is the temperature of the environment, say $20^{\circ} \mathrm{C}$.

\section{CONCLUSIONS AND FurTher WORK}

MPC of novel DER technologies seems promising as many operational activities undertaken at different levels of the electricity infrastructure (i.e., final user level, aggregate, load serving entity level, or even system level) can be performed better when incorporating future knowledge. Intelligent control is enabled by innovative ICT concepts. This paper has presented the detailed design of an MPC strategy for a grid-connected residential PEMFC system that operates in conjunction with an auxiliary heating system and heat storage options. Residential level MPC seems promising for reducing domestic electricity and gas costs.

Future work should include the implementation of both the thermal-led and MPC control strategies in mathematical software to evaluate the potential costs savings with MPC compared to thermal-led control. As simulation input, realistic electricity and heat demand patterns as well as realistic real-time electricity tariffs should be used.

\section{REFERENCES}

[1] M. Pehnt, M. Cames, C. Fischer, B. Praetorius, L. Schneider, K. Schumacher, and J. Vob, Micro Cogeneration: Towards Decentralized Energy Systems. Berlin: Springer, 2006.

[2] J. M. Maciejowski, Predictive Control with Constraints. Harlow, England: Prentice Hall, 2002.

[3] M. Houwing, R. R. Negenborn, B. De Schutter, and J. Hellendoorn, "Economic Advantages of Applying Model Predictive Control to Distributed Energy Resources: The Case of Micro-CHP Systems", In: Proceedings of the 16th Mediterranean Conference on Control and Automation, Ajaccio, France, 2008

[4] H. I. Onovwionaa and V. I. Ugursalb, "Residential cogeneration systems: review of the current technology", Renewable and Sustainable Energy Reviews, vol. 10, pp. 389-431, 2006.

[5] M. Dentice d'Accadia, M. Sasso, S. Sibilio, and L. Vanoli, "Microcombined heat and power in residential and light commercial applications", Applied Thermal Engineering, vol. 23, pp. 1247-1259, 2003.

[6] R. Fletcher and S. Leyffer, "Numerical Experience with Lower Bounds for MIQP Branch-And-Bound", SIAM Journal on Optimization, vol. 8, issue 2, pp. 604-616, 1998.

[7] M. W. Davis, A. Hunter Fanney, M. J. LaBarre, K. R. Henderson, and B. P. Dougherty, "Parameters affecting the performance of a residential-scale stationary fuel cell system", Journal of Fuel Cell Science and Technology, vol. 4, issue 2, pp. 109-115, 2007.

[8] R. Toonssen, "Personal Communication" (R. Toonssen is an expert in micro-CHP fuel cell systems at the Process and Energy department of the Delft University of Technology, Delft, The Netherlands), 2008.

[9] Y. Hamada and M. Nakamura, "Field performance of a polymer electrolyte fuel cell for a residential energy system", Renewable and Sustainable Energy Reviews, issue 9, pp. 345-362, 2004.

[10] G. Papaefthymiou, M. Houwing, M. P. C. Weijnen, and L. Van der Sluis, "Distributed Generation vs Bulk Power Transmission", In: Proceedings of the NGInfra-IEEE International Scientific Conference "Building Networks for a Brighter Future", Rotterdam, The Netherlands, 2008.

[11] R. R. Negenborn, Multi-Agent Model Predictive Control with Applications to Power Networks (Ph.D. thesis), Faculty of Mechanical, Maritime and Material Engineering. Delft: Delft University of Technology, 2007.

[12] S. Obara, "Dynamic characteristics of a PEM fuel cell system for individual houses", International Journal of Energy Research, issue 30, pp. 1278-1294, 2006.

\begin{tabular}{lll}
\hline Scenario & Thermal-led & MPC \\
\hline Base & 210.07 & 203.67 \\
Half gas & -138.82 & -146.78 \\
High demand & 565.67 & 553.54 \\
Large storage & 215.56 & 203.67 \\
\hline
\end{tabular}

